\title{
Correction to: Postmortem computed tomographic features in the diagnosis of drowning: a comparison of fresh water and salt water drowning cases
}

\author{
Makoto Sugawara $^{1}$ (1) $\cdot$ Koichi Ishiyama $^{1} \cdot$ Satoshi Takahashi ${ }^{1} \cdot$ Takahiro Otani $^{1} \cdot$ Makoto Koga $^{1} \cdot$ Osamu Watanabe $^{1}$. \\ Masazumi Matsuda ${ }^{1}$ - Tomoyuki Asano ${ }^{1}$. Noriko Takagi ${ }^{1} \cdot$ Tomoki Tozawa $^{1} \cdot$ Yuki Wada ${ }^{1}$ - Aoi Otaka ${ }^{1}$. \\ Satoshi Kumagai ${ }^{1} \cdot$ Motoko Sasajima $^{1} \cdot$ Manabu Hashimoto ${ }^{1}$
}

Published online: 24 July 2019

(C) Japan Radiological Society 2019

\section{Correction to: \\ Japanese Journal of Radiology (2019) 37:220-229 https://doi.org/10.1007/s11604-018-0802-8}

In the original publication, in Abstract, the second sentence of "Results" should read as:

Whereas in FWDCs, a significantly larger volume and lower density of fluid in the paranasal sinuses $(P=0.0195$ and $P=0.0104$, respectively), lower density of fluid in the central airways $(P=0.0077)$, lower stomach content density $(P=0.0216)$, lower density in the left atrium $(P=0.0029)$, and a difference of density between the atria $(\boldsymbol{P}=\mathbf{0 . 0 0 1 9})$ were observed.
In Table 3, in last line, the numbers of fresh water drowning and the $\mathrm{P}$ value were incorrect. The corrected Table 3 is given in this Correction.

In Results section, under the heading "CT number of the right and left atria", the third sentence should read as:

The difference in CT number between the bilateral atria

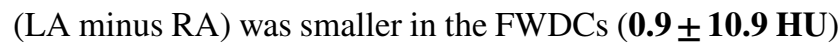
than in the SWDCs $(14.4 \pm 10.8 \mathrm{HU}, \boldsymbol{P}=\mathbf{0 . 0 0 1 9})$.

The original article can be found online at https://doi.org/10.1007/ s11604-018-0802-8.

Makoto Sugawara

masugawa@doc.med.akita-u.ac.jp

1 Division of Diagnostic Radiology, Akita University

Hospital, 1-1-1 Hondo, Akita, Akita 010-8543, Japan 
Table 3 Comparison of CT findings between fresh water and salt water drowning cases (mean \pm standard deviation, or number)

\begin{tabular}{|c|c|c|c|}
\hline & Fresh water drowning $(n=25)$ & Salt water drowning $(n=12)$ & $P$ value $^{\mathrm{a}}$ \\
\hline \multicolumn{4}{|l|}{ Lungs } \\
\hline Type 1 & $6(24.0 \%)$ & $8(66.7 \%)$ & 0.0274 \\
\hline Type 2 & 8 & 2 & 0.4447 \\
\hline Type $1+2$ & 7 & 2 & 0.6868 \\
\hline Others & 4 & 0 & 1.0000 \\
\hline \multicolumn{4}{|l|}{ Fluid in the paranasal sinus } \\
\hline Fluid accumulation existed (no. of cases, percentage) & $25(100.0 \%)$ & $12(100.0 \%)$ & (Unmeasurable) \\
\hline Mean volume of fluid (mL) & $13.3 \pm 7.7$ & $7.3 \pm 5.6$ & 0.0195 \\
\hline Mean CT number (HU) & $26.7 \pm 9.4$ & $35.9 \pm 9.2$ & 0.0104 \\
\hline \multicolumn{4}{|l|}{ Fluid in the central airway } \\
\hline Fluid accumulation existed (no. of cases, percentage) & $21(84.0 \%)$ & $10(83.3 \%)$ & 1.0000 \\
\hline Mean volume of fluid (mL) & $16.5 \pm 10.2(n=21)^{\mathrm{b}}$ & $20.8 \pm 10.5(n=10)^{\mathrm{b}}$ & 0.2992 \\
\hline Mean CT number (HU) & $12.0 \pm 7.4(n=21)^{\mathrm{b}}$ & $21.0 \pm 7.8(n=10)^{\mathrm{b}}$ & 0.0077 \\
\hline \multicolumn{4}{|l|}{ Stomach } \\
\hline Mean volume of the stomach $(\mathrm{mL})$ & $581.3 \pm 290.7$ & $641.9 \pm 280.9$ & 0.5499 \\
\hline Mean volume of stomach contents (mL) & $285.5 \pm 202.3$ & $324.5 \pm 194.4$ & 0.5790 \\
\hline Mean CT number of stomach contents (HU) & $8.5 \pm 13.3$ & $18.9 \pm 11.4$ & 0.0216 \\
\hline \multicolumn{4}{|l|}{ Cardiac chambers } \\
\hline Mean CT number of the right atrium (HU) & $48.0 \pm 9.5$ & $47.6 \pm 6.2$ & 0.8692 \\
\hline Mean CT number of the left atrium (HU) & $48.9 \pm 9.4$ & $62.0 \pm 11.4$ & 0.0029 \\
\hline $\begin{array}{l}\text { Mean difference of CT number between the left and } \\
\text { right atria (LA-RA, HU) }\end{array}$ & $0.9 \pm 10.9$ & $14.4 \pm 10.8$ & 0.0019 \\
\hline
\end{tabular}

\section{${ }^{a}$ Welch's $t$ test or Fisher's exact test}

${ }^{b}$ Fluid in the central airway was not present in four subjects in the FWDCs group and two subjects in the SWDCs group. Consequently, CT number of the fluid could not be determined 